\section{Development and validation of the Reward Deficiency Syndrome Questionnaire (RDSQ-29)}

\author{
Eszter Kótyuk ${ }^{1}$, Róbert Urbán ${ }^{1}$, Borbála Hende ${ }^{1,2}$, Mara Richman ${ }^{1}$, \\ Anna Magi1,2, Orsolya Király ${ }^{1}$, Csaba Barta ${ }^{3}$, Mark D Griffiths ${ }^{4}$, \\ Marc N Potenza ${ }^{5,6,7}$, Rajendra D Badgaiyan ${ }^{8}$, Kenneth Blum ${ }^{9}$ \\ and Zsolt Demetrovics ${ }^{1,10}$ iD
}

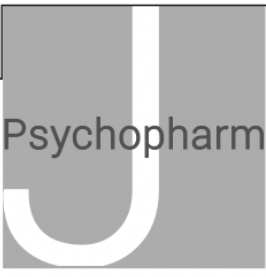

Journal of Psychopharmacology 1-14

○) The Author(s) 2022 Article reuse guidelines: sagepub.com/journals-permissions DOI: $10.1177 / 02698811211069102$ journals.sagepub.com/home/jop \$SAGE

\begin{abstract}
Background: The reward deficiency syndrome (RDS) integrates psychological, neurological, and genetic factors of addictive, impulsive, and compulsive behaviors. However, to date, no instrument has been validated to assess the RDS construct.

Aims: The present study developed and tested a tool to assess RDS.

Methods: Data were collected on two college and university samples. Exploratory factor analysis (EFA) and confirmatory factor analysis (CFA) were performed on Sample $1(N=1726)$, and confirmatory analysis was conducted on an independent sample $(N=253)$. Impulsivity and sensation-seeking were assessed.

Results: Based on EFAs, a 29-item Reward Deficiency Syndrome Questionnaire (RDSQ-29) was developed, containing four subscales (lack of sexual satisfaction, activity, social concerns, and risk-seeking behavior). CFA indicated good fit (comparative fit index (CFI) $=0.941$; Tucker-Lewis index $(T L I)=0.933$; root mean square error of approximation $($ RMSEA $)=0.068)$. Construct validity analysis showed strong relationship between sensationseeking and the RDS scale.

Conclusion: The RDSQ-29 is an adequate scale assessing psychological and behavioral aspects of RDS. The RDSQ-29 assesses psychological and behavioral characteristics that may contribute to addictions generally.

Keywords

Reward deficiency syndrome, Reward Deficiency Syndrome Questionnaire (RDSQ-29), addictive behaviors, substance use disorder, impulsive behaviors, compulsive behaviors
\end{abstract}

\title{
Introduction
}

The concept of Reward Deficiency Syndrome (RDS) was first introduced in 1996 by Blum and colleagues (Blum et al., 1996b; Blum et al., 1996a). The model unites addictive, impulsive, and compulsive behaviors and personality disorders. It proposes that the syndrome may emerge based on a combination of specific genetic variations, environmental stressors, and molecular effects relating to prolonged substance use or behavioral habituation. It suggests that due to these effects, a deficiency in reward mechanisms may emerge in which individuals seek out behaviors that may potentially stimulate reward pathways, with dopaminergic contributions hypothesized. The behaviors relating to RDS include substance use or other potentially addictive or risk-taking behaviors.

The hypodopamineric state/trait proposed as part of the RDS model states that hypodopaminergic function predisposes drug seeking and behaviors to release dopamine in reward circuits of the brain to overcome dopamine deficits (e.g., Blum et al., 2012). On the other hand, critiques of the RDS model 
suggest that it is not clear if dopamine receptor availability or sensitivity is deficient in this syndrome. Moreover, there is little consensus about the deficiency's basis or how it might increase drug use, and that drug seeking may be precipitated by increases in dopamine transmission rather than decreases (Leyton, 2014). Therefore, although it might would be more precise to employ a more generic description for this state such as deficit in dopamine receptor signaling, then (should this be 'then' or 'than'?) labeling it as 'hypodopamineric state/trait', since the theory itself refers to the involved neurobiological background as 'hypodopamineric', the same term is used here to adhere the original concept. I'm finding it a little hard to understand from a grammatical perspective. Maybe Marc could rephrase a little

The RDS model also proposes that specific molecular genetic factors have an important role in RDS-related behaviors. The hypothesized hypodopamineric state/trait is proposed to involve polygenetic factors. Reward-related genes highlighted in the addiction literature, second messengers, other enzymes and epigenetic messenger ribonucleic acid (mRNA) are proposed to influence neurotransmitter function in dopaminergic, serotonergic, opioidergic, GABAergic, adrenergic, and cholinergic pathways (Blum et al., 2017b). The initial concept of RDS emphasized the relevance of $D R D 2$ in $\mathrm{RDS}$ - a gene coding for the dopamine D2 receptor - since this variant has been shown to be an important factor in several addictions based on the extant literature (Blum et al., 1996b). The DRD2 had already been implicated in addictive behaviors, such as alcoholism (Noble et al., 1991; Blum et al., 1990) and other impulsive-addictive-compulsive behaviors (Blum et al., 1995a). The RDS model proposed that the A1 allele of the DRD2 genotype has a high predictive value of specific addictive behaviors. They used a mathematical method (i.e., Bayes Theorem) to predict the probability of specific addictive behaviors. They analyzed if the possession of the A1 allele associated with addictions by including addict groups and participant controls (Blum et al., 1995b, 1996b): A1 carriers have a $74 \%$ chance of developing one of the RDS-related disorders. The predictive value of the A1 allele in specific compulsive behaviors were as follows: severe alcoholism $14.3 \%$, severe cocaine dependence $12.3 \%$, polysubstance abuse $12.8 \%$, chemical dependency $28.3 \%$, severe overeating 
$18.6 \%$, ingestion behaviors $35.0 \%$, ADHD $16.0 \%$, cigarette smoking $41.5 \%$, pathological gambling 4.6\%, and Tourette's syndrome 5.5\%. However, subsequently, the extent to which the A1 allele relates to the dopamine D2 receptor versus other entities has been questioned, especially given linkage disequilibrium between DRD2 and ANKK1 (Yang et al., 2007). Besides, genetic basis of addictions is far from being completely identified, therefore further genetic markers of RDS are also possible.

More recently, Blum et al. (2014a) summarized findings regarding common neurogenetic factors implicated in addictions and described the relevance of dopamine pathways in the nucleus accumbens and striatrum to drug addictions. RDS also has implications for addiction treatment approaches (Gold et al., 2015). The theory of the 'Reward Deficiency Solution System' (Blum et al., 2014a; Blum et al., 2017a; Blum et al., 2015a) incorporates neurogenetic testing and meso-limbic manipulation. Blum and colleagues proposed that combinations of early genetic risk diagnosis, medical monitoring, and a nutrigenomic dopamine agonist may contribute to prevention, treatment with better recovery, and relapse prevention. However, given that dopamine agonists (e.g., in the setting of Parkinson's disease) have been associated with gambling problems and other addictive behaviors (Weintraub et al., 2010), these approaches should be considered cautiously and tested directly, especially since data indicate dopamine D2-like receptors might have a stronger role in specific substance addictions (e.g., stimulant use disorders) than in behavioral addictions (Potenza, 2018; Nutt et al., 2015).

Based on animal and human experiments some studies have suggested that a pro-dopamine regulator (i.e., KB220Z) may be a good medical compound to attenuate addictions (McLaughlin et al., 2018; Febo et al., 2017; Blum et al., 2015b; McLaughlin et al., 2013). KB220Z may enhance functional connectivity between reward and cognitive brain areas (nucleus accumbens, anterior cingulate gyrus, anterior thalamic nuclei, hippocampus, prelimbic and infralimbic loci), suggesting a possible mechanism for enhancing cognitive control over reward-driven behaviors.

As mentioned above, the concept of genetic risk factors for RDS has become more nuanced. The authors of the RDS model developed a so-called GARS model (Genetic Addiction Risk Score; Blum et al., 2014b) in which they proposed multiple genes, their polymorphisms, and associated risks for 
RDS. The list of the 11 proposed genetic risk factors mainly contains dopamine-related polymorphisms and gene variants related to the methylation and deacetylation of chromatin structure. This likely represents an incomplete list as genetic factors identified by genome-wide association studies (Gelernter et al., 2014b; Gelernter et al., 2015; Gelernter et al., 2014a; Kranzler et al., 2019) and incorporated into polygenic risk scores for substance and behavioral addictions (Lang et al., 2016) also warrant consideration.

In summary, the Reward Deficiency Syndrome is proposed to have a dopaminergic background. Authors of the model integrated dopamine-related neurological and genetic factors in the model based on selective literature reviews. The available case studies or empirical data regarding RDS are based on addictive disorders. There is an urgent need to have a well-defined phenomenological and behavioral description of RDS assessed utilizing a standardized tool to capture a specific set of neurological and genetic factors which drive these behaviors. The RDS model integrates psychological characteristics that may contribute to a wide range of psychiatric disorders often involving poor behavioral control (Blum et al., 1996a). A meta-analysis found inhibitory deficits associated with heavy use of or dependence on cocaine, 3,4-Methylenedioxymethamphetamine (MDMA), methamphetamine, tobacco, and alcohol, as well as in gambling disorder, supporting the view that substance and behavioral addictions are associated with impairments in inhibitory control (Smith et al., 2014). Zilverstand et al. (2018) systematically reviewed 105 task-related neuroimaging studies involving individuals with drug addictions and reported that specific brain networks (executive network, reward network) may have different roles in different stages of addiction (e.g., initiation versus compulsive use), but activities in these brain networks are similar in different types of drug addictions.

Furthermore, another review identified differences in brain function across addictions and proposed an integrative model, suggesting that neural deficits in the dorsal anterior cingulate cortex may constitute a hallmark neurocognitive deficit underlying addictive behaviors, such as impaired control (Luijten et al., 2014). A study investigated the relationship between inhibitory control, reward, 
and punishment sensitivity with respect to adolescent substance use. Based on structural equation modeling analyses, evidence of a moderating role for inhibitory control was observed in the association between reward sensitivity and substance use onset, suggesting that inhibitory control regulates reactivity toward incentives that may ultimately determine substance use behaviors (Kim-Spoon et al., 2016). With respect to potentially addictive behaviors, a meta-analysis found that individuals with internet gaming disorder were more likely to exhibit impaired response inhibition on neurocognitive tasks (Argyriou et al., 2017). A meta-analysis of 40 studies examining the cognitive performance of problematic internet use found that problematic internet use was also associated with impairment in inhibitory control (attentional inhibition, motor inhibition), decision-making, and working-memory performance (Ioannidis et al., 2019).

Impulsivity is an important transdiagnostic construct linked to substance (Verdejo-García et al., 2008; Acton, 2003; Coskunpinar et al., 2013; Stautz and Cooper, 2013) and behavioral (Grant and Chamberlain, 2014) addictions. Novelty-seeking and risk-taking personality features have also be implicated as possible predictors of substance use (Wills et al., 1994; Ersche et al., 2010; Wingo et al., 2016; Wills et al., 1998; Bidwell et al., 2015; Foulds et al., 2017; Zuckerman, 2007; Horvath et al., 2004) and non-substance addictive behaviors (Nower et al., 2004; Mehroof and Griffiths, 2010).

Anxiety, depression and anhedonia have been observed in substance-using populations (e.g., Garfield et al., 2014) and people with behavioral addictions (Müller et al., 2019; Andreassen et al., 2016; Marmet et al., 2019; Hou et al., 2019). These constructs have been linked to severity of gambling (Rømer Thomsen et al., 2009), compulsive internet use and video-gaming (Guillot et al., 2016).

These data suggest that RDS-related behaviors and disorders share common characteristics, impulsivity and sensation seeking are core psychological elements of these behaviors. The RDS proposes that besides these, a general 'insufficiency of usual feelings of satisfaction' also characterize them (p. 2 in Blum et al., 2012). However, empirical studies demonstrating the phenomenological concept of the RDS are lacking, and related psychological factors are speculative based on the RDS model and the clinical descriptions of the associated behaviors and disorders. 
In summary, evidence supports the concept of the RDS, and the RDS model reflects psychological and behavioral aspects of addictive, compulsive, and impulsive behaviors. Even though the neurological and genetic background of RDS have been investigated, to date no studies have sought to develop a scale to assess the RDS and examine measures linked to the RDS. Taking this into consideration, the present study sought to develop an instrument to assess the RDS and explore its correlates. We hypothesized that a scale assessing the RDS construct would be psychometrically sound (demonstrate good validity and reliability) and would relate to transdiagnostic constructs of impulsivity and sensation-seeking.

\section{Methods}

Here we report how we determined our sample size, all data exclusions, all manipulations, and all measures in the study. The datasets of the current study are available from the corresponding author on reasonable request. The final version of the developed tool, the RDSQ-29 is freely available in Appendix 1.

\section{Participants and procedures}

All data were collected in a pen-and-paper manner. Participants were recruited on a voluntary basis and received no compensation. Both samples included students of various disciplines. Measures were administered in Hungarian.

Sample 1. Sample 1 was a convenient sample of Hungarian young adults recruited from Hungarian colleges and universities. The data collection was conducted as part of the Psychological and Genetic Factors of the Addictive Behaviors (PGA) Study in the third and fourth data collection waves (Kotyuk et al., 2019). This sample included 1726 participants with a mean age of 21.0 years $(\mathrm{SD} \pm 2.0)$. The male/female ratio was $42.9 \% / 57.1 \%$. For exploratory factor analysis, this sample was randomly divided into four non-overlapping subsamples: Subsample $1(\mathrm{n}=424)$, Subsample $2(\mathrm{n}=424)$, Subsample $3(n=424)$, Subsample $4(n=454)$. Also see 'Data analysis strategy' section. 
Sample 2. This independent sample was a convenient university sample that included 253 Hungarian university students. The target sample size for the confirmatory factor analysis was based on the 'rule of thumb' which suggest 5 to 10 participants per item (Tinsley and Tinsley, 1987). Recruitment was advertised in university courses, and students participated on a voluntary basis. Mean age of the sample was 23.4 years $( \pm 5.1)$. Females were overrepresented $(72.7 \%)$ as compared to males $(27.3 \%)$. Participants completed the final 29-item version of the RDSQ (see Appendix 1).

Ethics. All participants provided written informed consent for the administered surveys. The study protocol was designed in accordance with guidelines of the Declaration of Helsinki and was approved by the Scientific and Research Ethics Committee of the Medical Research Council (ETT TUKEB). Survey data were based on self-report.

\section{Measures and development of the instrument}

Reward Deficiency Syndrome Questionnaire - The process of item generation. Despite the aforementioned neurobiological and genetic studies, the psychological (i.e., phenomenological) description of the syndrome has never been attempted previously. However, based on the aforementioned data and the psychiatric problems related to the syndrome, the following description was articulated. A person with RDS has reckless tendencies and frequently seeks new rewarding stimuli. Natural rewards, such as eating, intimacy, sex, exercising or other pleasurable activities of everyday life do not provide such individuals sufficient satisfaction. For this reason, they are predisposed to overuse these behaviors and/or to seek other behaviors that may provide additional stimulation. Individuals with RDS do not tend to experience relaxation in their lives. Instead, they are typically active and have difficulties quitting rewarding activities. Inactivity makes them feel bored and empty. As a next step in developing the Reward Deficiency Syndrome Questionnaire, the authors generated 72 items based on this definition based on available literature: Blum referred to RDS for example as 'an insufficiency of usual feelings of satisfaction' (Blum et al., 2012: 2), as 'an inability to derive reward from ordinary, everyday activities' or as '... an imbalance that...supplant an individual's 
feeling of well being with anxiety, anger or a craving for a substance that can alleviate the negative emotions' (Blum et al., 1996a: 132). Based on these studies, a prototypic profile of RDSQ was described and this description was turned into the 72 items. This was necessary because Participants completed the first 72-item version of the Reward Deficiency Syndrome Questionnaire (RDSQ, see below) for scale construction. Participants were instructed to read the statements referring to everyday human behaviors and to indicate the extent to which the statements were true for themselves on a 1 (totally disagree) to 4 (totally agree) Likert-type scale. As a first step, three independent experts were invited to review these 72 items in view of the initial statical analyses (including frequency tables and correlations) as well as the content of the items. Based on this initial review, the experts suggested excluding 21 items due to redundancy or not being properly related to the theoretical concept. Examples for the items removed at this stage: 'I usually get bored', 'I can even get bored of my favorite activities or hobbies if I engage in them for too long', 'I often change friends', 'I usually long for the next experience so intensely that I can't think about anything else'. Factor structure and psychometric properties of this 51-item version of the scale was assessed on Sample1 based on the factor analysis, a final 29-item version was developed (RDSQ-29, see Appendix 1) and tested on an independent sample (Sample2). Items of the RDSQ-29 try to capture the core nature of RDS, covering satisfaction, fulfillment, pleasure, activity in general and in regard to special, 'unusual' behaviors such as extreme sexual activity or sports.

Revised Barratt Impulsivity Scale - BIS-R-21. Participants in the confirmatory factor analysis sample also completed the revised Barratt Impulsivity Scale (BIS-R-21) (Patton et al., 1995). The BIS-R-21 includes 21 items and is scored on a four-point Likert-type scale from 1 (rarely/never) to 4 (almost always/always). It assesses three impulsivity factors: Cognitive Impulsiveness, Behavioral Impulsiveness, and Impatience and Restlessness. The Hungarian BIS-R-21 showed good validity values (Kapitány-Fövény et al., 2020). The total and the scale scores are the sum of all the items, with higher values representing higher impulsivity. The cognitive impulsivity scale measures lack of 
planning, instability and emotional imbalance (e.g., 'I plan tasks carefully', revised item). The behavioral impulsivity scale reflects a form of impulsivity which has a mainly behavioral, motor manifestation (e.g., 'I do things without thinking'). The impatience and restlessness scale measures difficulties in concentrating on tasks or implementing behavior (e.g., 'I change hobbies'). Earlier studies reported sufficient internal consistency values (Varga et al., 2012; Maraz et al., 2016). The mean total BIS-R-21 score on Sample 2 in the present study was $52.48(\mathrm{SD} \pm 5.1)$ and the Cronbach alpha was 0.803 .

The Brief Sensation Seeking Scale - BSSS. The Brief Sensation Seeking Scale demonstrated good psychometric properties (Hoyle et al., 2002). It comprises eight items and assesses sensation seeking on four subscales: thrill and adventure seeking (e.g., 'I like to do frightening things'), experience seeking (e.g., 'I would like to take off on a trip with no pre-planned routes or timetables'), disinhibition (e.g., 'I like wild parties'), and boredom susceptibility (e.g., 'I get restless when I spend too much time at home'). Participants rate how much they agree with the scale statements on a summative scale ranging between 1 (do not agree) and 5 (agree). The scale is scored as the sum of the items, where higher mean score represents higher sensation seeking. The total mean score on the BSSS in the present study was $23.00(\mathrm{SD} \pm 5.5)$, and the Cronbach alpha was 0.745 .

Both the Barratt Impulsivity Scale and the Brief Sensation Seeking Scale have been studied extensively in relation to addiction. For example, it has been shown that impulsivity measured by the Barratt Impulsivity Scale is a marker for vulnerability to eating problems (Meule et al., 2017), it correlates for example with alcohol use (Coskunpinar et al., 2013) and with internet addiction (Choi et al., 2014) as well. It is also a powerful predictor of addiction treatment outcomes (e.g., LópezTorrecillas et al., 2014). The BSSS is a strong predictor of the intention to try cannabis in the future, and also worked at identifying adolescents at risk for drinking and smoking (Sargent et al., 2010; Stephenson et al., 2007). 


\section{Data analysis strategy}

To achieve the study goals, we applied increasingly restrictive solutions of latent structure including a series of exploratory factor analyses (EFAs) and two separate confirmatory factor analyses (CFAs). Both EFAs and CFAs were performed with MPLUS 7.4. All items were treated as an ordinal scale; therefore, we applied diagonally weighted least squares (WLSMV) estimation method in both EFAs and CFAs.

In the EFAs, we applied multiple sources during the decision of factor number: (i) selecting the solution where eigenvalues level off; and, (ii) goodness of fit indices including the root-mean-square error of approximation (RMSEA) which should be equal or smaller than 0.05 for a good fit , and Tucker-Lewis index (TLI) which should reach 0.90 , but its optimal value is above 0.95 (Hu and Bentler, 1999). In the EFAs, we applied bifactor rotation (bi-geomin). We have selected the bifactor rotation because we assumed that reward deficiency syndrome as a hypodopaminergic trait is a general, overarching construct or dimension reflected in different behavioral domains. The bi-factor model is a useful statistical approach to describe dimensionality, especially when a general factor is assumed theoretically (Cai et al., 2011). The bifactor measurement model allows for the items to load on an overall primary factor such as reward deficiency and also to have a secondary loading on a specific dimension such as sensation-seeking. In a bifactor measurement model, the general and specific factors are not assumed to correlate with each other; therefore, they are orthogonal to each other.

In the CFAs, goodness of fit was evaluated using RMSEA and its $90 \%$ confidence interval ( $90 \%$ CI), a $p$-value smaller than .05 for test of close fit, standardized root-mean-square residual (SRMR), comparative fit index (CFI), and Tucker-Lewis Fit Index (TLI). As Brown and Kline (2005) recommended, multiple indices were selected in order to provide different information for evaluating model fit. To conduct the analyses, we randomly selected four non-overlapping groups from Sample 1. Subsample $1(N=424)$ was used to perform an initial EFA of the original 51 items (see Appendix). Subsample $2(N=424)$ was used to conduct a separate EFA to cross-validate the factor structure found in the first analysis. In this step, we established the number of factors and we selected the items for 
further analyses. Subsample $3(N=424)$ was used to conduct an EFA on the selected 51 items to crossvalidate the factor structure and reinforce the item selection. Subsamples 1-3 informed the specification of an appropriate CFA solution in Subsample $4(N=454)$. In order to validate the measurement model on an independent sample, we conducted a CFA using a separate university sample (Sample 2; $N=253$ ). We also performed a CFA with covariates involving gender, sensationseeking, and impulsivity in order to provide support for the new scale's construct validity.

In order to quantify the degree of uni-dimensionality in bi-factor models, the percent of common variance attributable to the general factor was determined by calculating the explained common variance (ECV; Ten Berge and Sočan, 2004; Bentler, 2009). We also used omega and omega hierarchical indices to assess how precisely a self-reported symptom scale score assessed the combination of general and specific constructs and a certain target construct (e.g., Brunner et al., 2012) (e.g., Brunner et al., 2012). Omega may assist in determining which composite scales possess sufficient reliable variance to be interpreted. It is a model-based reliability estimate that combines higher-order and lower-order factors. In the case of a bi-factor model, omega-hierarchical (in contrast) is the modelbased reliability estimate of one target construct with the influences of the others removed. There is no clearly defined cut-off for an omega-hierarchical coefficient. Reise et al. (2013) tentatively proposed relatively strict advice to evaluate omega-hierarchical values for specific factors: namely, the minimum value would be greater than 0.50 and the preferred value would be closer to 0.75 (see also Reise, 2012).

\section{Results}

\section{Exploratory factor analyses}

EFAs with bifactor geomin rotation in two non-overlapping subsamples (Subsample 1 and Subsample 2) were performed to establish the number of factors and the items for further analyses. Table 1 summarizes the results of these factor analyses. To keep the results more comparable and to make it visually easier to follow the similar patterns by the subsamples, the results are presented by 
the eigenvalues and fit indices for all three analyses. Based on the eigenvalues and fit indices, fivefactor solutions were selected. The decrease of eigenvalues levelled off after the fifth factor in both samples, e.g., in case of Subsample 1 the eigenvalue dropped from 1.9 to 1.82 , and in case of Subsample 2 the eigenvalue dropped from 2.02 to 1.82 from the fifth to the sixth factor. The fit indices support both four-factor and five-factor solutions. RMSEA dropped below 0.05 and TLI approached 0.90 closely in both samples. In order to avoid under-factoring, we selected five-factor solutions.

After the decision regarding the number of factors, we performed the item selection procedure. We included items which had salient factor loadings $(\geq 0.30)$ at least on the general factor in Subsample 1 and Subsample 2 (Table 2). We also considered the relative homogeneity of factor loadings in the two separate samples. After the extensive selection of items, we performed another EFA with Subsample 3 which again supported the five-factor solution. For fit indices of different factor solutions in Subsample 3, see Table 1. The five factors comprise four specific factors, and the general factor (Table 3). The general factor represented a reward deficiency tendency. The first specific factor refers to the 'Lack of sexual satisfaction' because the items reflect difficulties feeling sexually satisfied and having multiple sexual partners. The second specific factor reflected a tendency for risk-seeking behaviors. Some items here had a specific focus on searching for risky behavior in sports, while other items covered risk-seeking behavior more generally. The third factor named activity reflected difficulties tolerating inactivity and frequent seeking of activity. The fourth specific factor, named social concerns, contains two items reflecting significant others' worries about individuals' lifestyle and overstimulation. There are an additional fourteen items which only load on the general reward deficiency tendency factor without generating another independent factor.

\section{Confirmatory factor analyses}

In order to cross-validate the model, we performed a bifactor CFA on Subsample 4. Because of the difficulty of the model identification in the strictly CFA model, we applied bifactor exploratory structural equation modeling approach (Marsh et al., 2014). All items were used as indicators of 
general factors. Items having a salient factor loading $(>0.40)$ on other factors in the EFAs were also used as anchor indicator of a specific factor. Cross loadings were allowed. Orthogonal target rotation was used. However, some items loaded only on the general factor (Table 4). The fit indices were close to acceptable $\left(\chi^{2}=1146.6, \mathrm{df}=323, p<0.001 ; \mathrm{RMSEA}=0.07590 \% \mathrm{CI} \quad[0.070-0.080] ; \mathrm{CFI}=0.910\right.$; $\mathrm{TLI}=0.887$ ); therefore, we examined the modification indices in order to identify local misfits. Freeing the error covariance between two items ("Often I want to feel stimulated no matter what I have to do to get it." And "I often want a good time no matter what I have to do to get it") improved the model fit to the acceptable level $\left(\chi^{2}=1045.8, \mathrm{df}=322, p<0.001 ;\right.$ RMSEA $=0.070$ 95\%CI [0.066-0.075]; $\mathrm{CFI}=0.921 ; \mathrm{TLI}=0.901 ; \mathrm{SRMR}=0.062$ ). Factor loadings, explained common variance, omega, and omega hierarchicals are presented in Table 4. All items loaded significantly on the general factor and their respective specific factors (see salient factor loadings in bold in Table 4). Estimation of the ECV for the bi-factor model showed that the general reward deficiency factor explained $68 \%$ of the common variance. The ECVs for the four specific factors ranged from 5\% to $10 \%$.

In order to evaluate measurement precision of each subscale in assessing the blend of general reward deficiency and specific tendencies, we calculated coefficient omega. For assessing whether a specific factor measured only specific tendencies as intended or merely general reward deficiency, we computed the omega hierarchical coefficient with the modification that is necessary to take into account correlations between specific factors. Omega coefficients ranged from 0.66 to 0.97 (see Table 4). The omega hierarchical is very strong in case of the general factor (0.94) which implies that variance in the sum score is explained by the general factor supporting the uni-dimensionality of the construct. In addition, the range of omega hierarchical of specific factors was between $0.27-0.55$, which is below what Reise (2012) would generally recommend. However, in the case of three factors, lack of sexual satisfaction, activity and social concerns, the omega hierarchicals were close to 0.50 . Therefore, the variance of the three factor scores represent relatively largely their specific meanings. In case of risk-seeking, the specific score should be used cautiously. 
We performed further cross-validation with an independent university sample (Sample 2). In this case we performed the traditional CFA analysis. In order to solve the identification problem we fixed the factor loadings of item 13 and 18 to be equal. Two error covariances were allowed between Items 15 and 24 ('I need more stimulation than others'; 'I need more excitement than others') and between Items 25 and 29 ('I often want a good time no matter what I have to do to get it'; 'Often, I want to feel stimulated no matter what I have to do to get it') due to the close similarity in their content. The model yielded an acceptable degree of fit $\left(\chi^{2}=800.7, \mathrm{df}=361, p<0.001 ; \mathrm{RMSEA}=0.06990 \% \mathrm{CI}[0.063-0.076]\right.$; $\mathrm{CFI}=0.938 ; \mathrm{TLI}=0.93, \mathrm{SRMR}=0.080$ ). The factor loadings explaining common variance, omega, and omega hierarchicals are presented in Table 5. All factor loadings were significant. Estimation of the ECV for the bi-factor model provided evidence that the general reward deficiency factor explained $69 \%$ of the common variance. The ECVs for the four specific factors ranged from $4 \%$ to $10 \%$. The omega hierarchical of the general factor was 0.90 , similar to the previous analysis. The omega hierarchical coefficients of specific factors ranged from 0.33 to 0.58 (Table 5).

\section{Confirmatory factor analyses with covariates}

As a next step, the relationship between RDS and RDS linked dimensions was explored. In order to investigate the construct validity of the general reward deficiency factor and the specific factors, we performed a CFA on the confirmatory sample (Sample 2) with covariates, in which the general and specific factors were regressed on gender, sensation-seeking, and impulsivity (Table 6). The analysis was first carried out on the full model. However, in this case the suppressor effect of the general factor resulted in counter-intuitive negative correlations. Therefore, Partial Model 1 (for the general factor) and Partial Model 2 (for the four specific factors) were also calculated to provide a more precise description of the relationship between the factors and the further assessed personality traits. The general reward deficiency factor was associated with gender, sensation-seeking and impulsivity. Males showed stronger reward deficiency tendencies (males were coded as 2 in the database). Higher sensation-seeking and higher impulsivity statistically predicted a higher degree of reward deficiency. 
The regression coefficients on the specific factors also presented evidence of convergent validity of these constructs. Based on the Partial Model 2 in Table 6, where the reward deficiency tendency is excluded, higher levels of sensation-seeking and impulsivity were associated with higher levels of activity and social concerns. Higher sensation-seeking was also associated with higher scores on the risk-seeking behavior and lack of sexual satisfaction factors.

\section{Descriptive statistics of the Reward Deficiency Scale}

Gender differences in the RDSQ total score and on the subscales were also tested. Males showed significantly higher mean score on the RDSQ total scale and lack of sexual satisfaction, social concerns, and risk-seeking behavior subscales, while females showed a higher mean score on the activity subscale (Table 7). Table 7 also summarizes the descriptive statistics on the total Sample 1 and Sample 2 (means and standard deviations of the total RDSQ and subscales). The Cronbach alpha values of the RDSQ were sufficient. In Sample 1, the 72-item version of the RDSQ had a very good Cronbach alpha $(\alpha=0.865)$, as did the 51-item $(\alpha=0.843)$ and the 29 -item $(\alpha=0.895)$ versions. Cronbach alpha on Sample 2 was 0.917 for the RDSQ-29.

\section{Discussion}

The goal of the present study was to develop and test the psychometric properties of the RDSQ instrument. Data suggest similarities in the symptomology, etiology, and pathophysiology of different types of behavioral addictions and substance-related disorders which may share psychological underpinnings. Integrative theories cover a wide range of behaviors. For example, the component model of addictions (Griffiths (2005) argues that addictions share six basic characteristics. The Obsessive-Compulsive Spectrum Disorder (OCSD) model (Hollander, 1993; Hollander and Wong, 1995) suggests that there are some shared obsessive-compulsive features in disorders from different diagnostic categories. Additionally, the Syndrome Model of Addiction (Shaffer et al., 2004) argues 
that specific factors may lead to the development of an addiction syndrome, which can manifest in many different ways, suggesting that addictions can have multiple expressions but a common etiology.

The RDS is another model that attempts to conceptualize shared psychological and biological mechanisms of different disorders. Based on the RDS model and proposed biological correlates, the psychological manifestations of the RDS could include anhedonia, restlessness, seeking of new situations and adventures, and needing high levels of stimulation, given that "normal" rewards are not perceived as satisfactory. Although the RDS shows some relatedness to specific psychological constructs, such as sensation-seeking and impulsivity, it appears to have specific characteristics associated with reward and dissatisfaction.

While the neurobiological background of RDS has previously been described, the present study is the first attempt to measure the psychological features and behavioral tendencies related to the syndrome. Therefore, the primary aim of the present study was to develop a standardized psychometric tool to assess RDS severity. Based on exploratory and confirmatory factor analyses, a 29-item questionnaire was developed that assesses a general reward deficiency tendency and four subdimensions: lack of sexual satisfaction, activity, social concerns, and risk-seeking behavior. Construct validity of the RDSQ-29 was also tested. RDS severity showed a moderate correlation with sensationseeking and a modest correlation with impulsivity. Consequently, the RDSQ-29 demonstrated some similarities with theoretically associated psychological constructs, but uniqueness of the assessed construct is also suggested.

In case of the subscales, the lack of sexual satisfaction subscale moderately correlated with sensation-seeking. Feeling as if one is never getting enough sex and having more than one sexual partner at any one time showed some relatedness with sensation-seeking. It appears that the overlap between sensation-seeking and lack of sexual satisfaction may be associated with urges to seek out sexual sensations (e.g., 'I regularly change my sexual partners.'). The activity subscale showed a moderate relationship with impulsivity and sensation-seeking, which is in line with the concept of RDS. Always seeking out new activities, looking for the next thing to do, and getting annoyed by 
perceived inactivity share some dimensions with impulsivity and sensation-seeking (e.g., 'I'm almost always active.'). The moderate relationship between the social concerns factor, sensation-seeking, and impulsivity suggests that the factor concentrates on social opinions regarding one's sensation-seeking and impulsive activities (e.g., 'My friends and family often worry about my lifestyle.'. The riskseeking behavior subscale showed a strong correlation with sensation-seeking, suggesting that living dangerously, engaging in extreme activities, and taking risks are strongly associated with sensationseeking (e.g., 'Extreme sports stimulate me.'). In conclusion, the RDSQ-29 and its subscales showed moderate relationships with sensation-seeking and impulsivity. As the RDS model integrates psychological dimensions related to addictions, these results are in line with previous findings. Impulsivity and sensation-seeking have been implicated in addictive behaviors (Verdejo-García et al., 2008; Acton, 2003; Coskunpinar et al., 2013; Stautz and Cooper, 2013; Grant and Chamberlain, 2014; Ersche et al., 2010; Wills et al., 1994; Mehroof and Griffiths, 2010; Nower et al., 2004; Zuckerman, 2007; Horvath et al., 2004). Nonetheless, besides the strong relationship between the risk-seeking behavior scale of the RDSQ-29 and sensation-seeking, the other RDSQ subscales and total score only related to sensation-seeking and impulsivity moderately, suggesting that the RDS trait is a unique construct. There is an abundance of data pointing towards the association between addictive behaviors and psychological dimensions. The newly developed psychometric instrument, the RDSQ, tries to integrate such psychological elements which have been shown as important factors in addictions, developing a psychometric instrument that assesses the RDS.

The RDSQ was developed based on the theoretical concept of the RDS. Since little empirical evidence is available in the literature concerning the conceptualization of RDS, the empirical validation, exploration of the relationship between RDS tendencies and addictive behaviors, and related psychological dimensions are needed. Future studies should focus on investigating the link between RDS severity, impulsivity, sensation-seeking, inhibition processes, reward dependence, delay discounting, and personality disorders. Furthermore, the development of the RDSQ-29 was conducted 
on a young, college and university sample. Replication is needed in other samples, especially on clinical samples with participants diagnosed with substance use disorders or behavioral addictions.

Limitations of the present study include the convenience self-selected samples, the self-report data and the Hungarian population only. Since data were collected only from undergraduates, further construct validity analyzes - with data from individuals likely to have RDS, addictions or the genetic risk factors associated with it - are necessary to prove the link between RDSQ and the definition of RDS as previously used in the literature. Also, the relationship between the score on the RDSQ and the severity of addictive behaviors and other factors that correspond to severity of RDS are need to be validated. To support the trait construct of RDS, RDSQ factor scores need to be tested over time to assess within individual stability. Measures of reward functioning and addiction associated clinical constructs (such as anhedonia, depression, and anxiety) need to be tested as part of future convergent validity analysis. Impulsivity and sensation-seeking are often associated with antisociality (or asociality) which might be present in four of the 14 unique-loading items of the general RDS scale (i.e., "I desire to participate in all aspects of life no matter the limits"; "No pain or tiredness can deter me from doing something that I am passionate about"; "I often want a good time no matter what I have to do to get it"; "Often, I want to feel stimulated no matter what I have to do to get it."). These items suggest a willful disregard for normal constraints on behavior indicating deviant motivation as a possible linked dimension of RDS. Future research of RDS should investigate the possible role of deficient punishment sensitivity in RDS. Also, the number of participants in Sample 2 might have been a bit small for carrying out confirmatory factor analysis for a 29-item questionnaire. It also has to be noted, that the present study does not provide data on causality, proving that the activities measured by the RDSQ are a direct result of the RDS state. For example, seeking out new adventures, enjoying activities that give an adrenaline rush can equally be explained by a hyperactive reward system resulting from an increased motivational drive to engage in reward and sensation seeking behavior (Leyton, 2014). Therefore, further studies investigating the Reward Deficiency Syndrome, and the RDSQ are needed. 
In conclusion, this is the first attempt to operationalize the phenomenological, psychological aspects of the reward deficiency syndrome. The RDSQ-29 is an adequate and robust scale to assess the psychological features and behavioral tendencies associated with the RDS. The final 29-item version of the scale is relatively short and easy to administer and score (see Appendix 1). The RDS model suggests that impairments in the reward system circuitry can lead to the development of the RDS, which on a behavioral level can manifest in many different types of impulsive and addictive behaviors. The development of the RDSQ-29 provides an opportunity to investigate genetic, neurological, and psychological features related to the RDS, the role of the RDS in the development of addictions. 


\section{Funding}

This work was supported by the Hungarian National Research, Development and Innovation Office (Grant numbers: KKP126835, ELTE Thematic Excellence Programme 2020, KP2020-IKA-05). Kenneth Blum was supported by R41MD012318/MD/NIMHD. Orsolya Király was supported by the János Bolyai Research Scholarship of the Hungarian Academy of Sciences and by the ÚNKP-19-4 New National Excellence Program of the Ministry for Innovation and Technology. Csaba Barta was supported by funding from the Merit-prize fellowship of Semmelweis University, the Bolyai János research fellowship of the Hungarian Academy of Sciences BO/00987/16/5, the ÚNKP-18-4 of the new National Excellence Program of the Ministry of Human Capacities and the Baron Munchausen Program of the Institute of Medical Chemistry, Molecular Biology and Pathobiochemistry, Semmelweis University. Marc Potenza received support from the Connecticut Council on Problem Gambling, the Connecticut Department of Mental Health and Addiction Services and the National Center for Responsible Gaming. The views presented in this manuscript are those of the authors and the funding agencies did not have influence into the content of the manuscript beyond provision of financial support.

\section{Conflict of interest}

Mark D. Griffiths' university currently receives research funding from Norsk Tipping (the gambling operator owned by the Norwegian Government). Mark D. Griffiths has also received funding for a number of research projects in the area of gambling education for young people, social responsibility in gambling and gambling treatment from Gamble Aware (formerly the Responsible Gambling Trust), a charitable body which funds its research program based on donations from the gambling industry. Mark D. Griffiths regularly undertakes consultancy for various gaming companies in the area of social responsibility in gambling. Marc Potenza discloses the following. Marc Potenza has consulted for Opiant Therapeutics, Game Day Data, the Addiction Policy Forum, AXA and Idorsia Pharmaceuticals; has received research support from Mohegan Sun Casino and the National Center 
for Responsible Gaming; has participated in surveys, mailings or telephone consultations related to drug addiction, impulse-control disorders or other health topics; has consulted for and/or advised gambling and legal entities on issues related to impulse-control/addictive disorders; has provided clinical care in a problem gambling services program; has performed grant reviews for researchfunding agencies; has edited journals and journal sections; has given academic lectures in grand rounds, CME events and other clinical or scientific venues; and has generated books or book chapters for publishers of mental health texts. Zsolt Demetrovics' university receives funding from Szerencsejáték Ltd. to maintain a telephone helpline service for problematic gambling. ZD has also been involved in research on responsible gambling funded by Szerencsejáték Ltd. and the Gambling Supervision Board and provided educational materials for Szerencsejáték Ltd's responsible gambling program. 


\section{References}

Acton GS. (2003) Measurement of impulsivity in a hierarchical model of personality traits: implications for substance use. Substance Use and Misuse 38: 67-83.

Andreassen CS, Billieux J, Griffiths M, et al. (2016) The relationship between addictive use of social media and video games and symptoms of psychiatric disorders: A large-scale cross-sectional study. Psychology of Addictive Behaviors 30: 252.

Argyriou E, Davison CB and Lee TTC. (2017) Response inhibition and internet gaming disorder: a metaanalysis. Addictive Behaviors 71: 54-60.

Bentler PM. (2009) Alpha, dimension-free, and model-based internal consistency reliability. Psychometrika 74: 137.

Bidwell LC, Knopik VS, Audrain-Mcgovern J, et al. (2015) Novelty seeking as a phenotypic marker of adolescent substance use. Substance Abuse: Research and Treatment 9s1: SART.S22440.

Blum K, Cull J, Braverman E, et al. (1996a) Reward deficiency syndrome. American Scientist 84: 132-145.

Blum K, Febo M, Badgaiyan RD, et al. (2017a) Common neurogenetic diagnosis and meso-limbic manipulation of hypodopaminergic function in reward deficiency syndrome (RDS): changing the recovery landscape. Current Neuropharmacology 15: 184-194.

Blum K, Febo M, McLaughlin T, et al. (2014a) Hatching the behavioral addiction egg: Reward Deficiency Solution System (RDSS) as a function of dopaminergic neurogenetics and brain functional connectivity linking all addictions under a common rubric. Journal of Behavioral Addictions 3: 149-156.

Blum K, Febo M, Smith DE, et al. (2015a) Neurogenetic and epigenetic correlates of adolescent predisposition to and risk for addictive behaviors as a function of prefrontal cortex dysregulation. Journal of Child and Adolescent Psychopharmacology 25: 286-292.

Blum K, Gardner E, Oscar-Berman M, et al. (2012) "Liking" and "wanting" linked to Reward Deficiency Syndrome (RDS): hypothesizing differential responsivity in brain reward circuitry. Current Pharmaceutical Design 18: 113-118.

Blum K, Gold M, Demetrovics Z, et al. (2017b) Substance use disorder a bio-directional subset of reward deficiency syndrome. Frontiers in Bioscience 22: 1534-1548.

Blum K, Liu Y, Wang W, et al. (2015b) rsfMRI effects of KB220Z on neural pathways in reward circuitry of abstinent genotyped heroin addicts. Postgraduate Medicine 127: 232-241.

Blum K, Noble EP, Sheridan PJ, et al. (1990) Allelic association of human dopamine D2 receptor gene in alcoholism. JAMA 263: 2055-2060.

Blum K, Oscar-Berman M, Demetrovics Z, et al. (2014b) Genetic Addiction Risk Score (GARS): molecular neurogenetic evidence for predisposition to Reward Deficiency Syndrome (RDS). Molecular Neurobiology 50: 765-796.

Blum K, Sheridan PJ, Wood RC, et al. (1995a) Dopamine D2 receptor gene variants: association and linkage studies in impulsive-addictive-compulsive behaviour. Pharmacogenetics 5: 121-141.

Blum K, Sheridan PJ, Wood RC, et al. (1996b) The D2 dopamine receptor gene as a determinant of reward deficiency syndrome. Journal of the Royal Society of Medicine 89: 396-400.

Blum K, Wood RC, Braverman ER, et al. (1995b) The D2 dopamine receptor gene as a predictor of compulsive disease: Bayes' theorem. Functional Neurology 10: 37-44.

Brunner M, Nagy G and Wilhelm O. (2012) A tutorial on hierarchically structured constructs. Journal of Personality 80: 796-846.

Cai L, Yang JS and Hansen M. (2011) Generalized full-information item bifactor analysis. Psychological Methods 16: 221-248.

Choi J-S, Park SM, Roh M-S, et al. (2014) Dysfunctional inhibitory control and impulsivity in Internet addiction. Psychiatry Research 215: 424-428.

Coskunpinar A, Dir AL and Cyders MA. (2013) Multidimensionality in impulsivity and alcohol use: a metaanalysis using the UPPS model of impulsivity. Alcoholism: Clinical and Experimental Research 37: 1441-1450.

Ersche KD, Turton AJ, Pradhan S, et al. (2010) Drug addiction endophenotypes: impulsive versus sensationseeking personality traits. Biological Psychiatry 68: 770-773.

Febo M, Blum K, Badgaiyan RD, et al. (2017) Enhanced functional connectivity and volume between cognitive and reward centers of naive rodent brain produced by pro-dopaminergic agent KB220Z. PloS One 12: e0174774.

Foulds JA, Boden JM, Newton-Howes GM, et al. (2017) The role of novelty seeking as a predictor of substance use disorder outcomes in early adulthood. Addiction 112: 1629-1637. 
Garfield JBB, Lubman DI and Yücel M. (2014) Anhedonia in substance use disorders: A systematic review of its nature, course and clinical correlates. Australian and New Zealand Journal of Psychiatry 48: 36-51.

Gelernter J, Kranzler HR, Sherva R, et al. (2015) Genome-wide association study of nicotine dependence in American populations: identification of novel risk loci in both African-Americans and EuropeanAmericans. Biological Psychiatry 77: 493-503.

Gelernter J, Kranzler HR, Sherva R, et al. (2014a) Genome-wide association study of opioid dependence: multiple associations mapped to calcium and potassium pathways. Biological Psychiatry 76: 66-74.

Gelernter J, Sherva R, Koesterer R, et al. (2014b) Genome-wide association study of cocaine dependence and related traits: FAM53B identified as a risk gene. Molecular Psychiatry 19: 717-723.

Gold MS, Badgaiyan RD and Blum K. (2015) A shared molecular and genetic basis for food and drug addiction: overcoming hypodopaminergic trait/state by incorporating dopamine agonistic therapy in psychiatry. Psychiatric Clinics of North America 38: 419-462.

Grant JE and Chamberlain SR. (2014) Impulsive action and impulsive choice across substance and behavioral addictions: Cause or consequence? Addictive Behaviors 39: 1632-1639.

Griffiths M. (2005) A 'components' model of addiction within a biopsychosocial framework. Journal of Substance Use 10: 191-197.

Guillot CR, Bello MS, Tsai JY, et al. (2016) Longitudinal associations between anhedonia and internet-related addictive behaviors in emerging adults. Computers in Human Behavior 62: 475-479.

Hollander E. (1993) Obsessive-compulsive spectrum disorders: An overview. Psychiatric Annals 23: 355-358.

Hollander E and Wong CM. (1995) Obsessive-compulsive spectrum disorders. Journal of Clinical Psychiatry 56 Suppl 4: 3-6.

Horvath LS, Milich R, Lynam D, et al. (2004) Sensation seeking and substance use: a cross-lagged panel design. Individual Differences Research 2: 175-183.

Hou XL, Wang HZ, Hu TQ, et al. (2019) The relationship between perceived stress and problematic social networking site use among Chinese college students. Journal of Behavioral Addictions 8: 306-317.

Hoyle R, H., Stephenson M, T., Palmgreen P, et al. (2002) Reliability and validity of a brief measure of sensation seeking. Personality and Individual Differences 32: 401-414.

$\mathrm{Hu}$ Lt and Bentler PM. (1999) Cutoff criteria for fit indexes in covariance structure analysis: Conventional criteria versus new alternatives. Structural Equation Modeling: A Multidisciplinary Journal 6: 1-55.

Ioannidis K, Hook R, Goudriaan AE, et al. (2019) Cognitive deficits in problematic internet use: meta-analysis of 40 studies. British Journal of Psychiatry: 1-8.

Kapitány-Fövény M, Urbán R, Varga G, et al. (2020) The 21-item Barratt Impulsiveness Scale Revised (BISR-21): An alternative three-factor model. Journal of Behavioral Addictions 9: 225-246.

Kim-Spoon J, Deater-Deckard K, Holmes C, et al. (2016) Behavioral and neural inhibitory control moderates the effects of reward sensitivity on adolescent substance use. Neuropsychologia 91: 318-326.

Kotyuk E, Farkas J, Magi A, et al. (2019) The psychological and genetic factors of the addictive behaviors (PGA) study. International Journal of Methods in Psychiatric Research 28: e1748.

Kranzler HR, Zhou H, Kember RL, et al. (2019) Genome-wide association study of alcohol consumption and use disorder in 274,424 individuals from multiple populations. Nature Communications 10: 1499.

Lang M, Leménager T, Streit F, et al. (2016) Genome-wide association study of pathological gambling. European Psychiatry 36: 38-46.

Leyton M. (2014) What's deficient in reward deficiency? Journal of Psychiatry and Neuroscience 39: 291-293.

López-Torrecillas F, Perales JC, Nieto-Ruiz A, et al. (2014) Temperament and Impulsivity Predictors of Smoking Cessation Outcomes. PloS One 9: e112440.

Luijten M, Machielsen MW, Veltman DJ, et al. (2014) Systematic review of ERP and fMRI studies investigating inhibitory control and error processing in people with substance dependence and behavioural addictions. Journal of Psychiatry and Neuroscience 39: 149-169.

Maraz A, Ando B, Rigo P, et al. (2016) The two-faceted nature of impulsivity in patients with borderline personality disorder and substance use disorder. Drug and Alcohol Dependence 163: 48-54.

Marmet S, Studer J, Wicki M, et al. (2019) Unique versus shared associations between self-reported behavioral addictions and substance use disorders and mental health problems: A commonality analysis in a large sample of young Swiss men. J Behav Addict 8: 664-677.

Marsh HW, Morin AJS, Parker PD, et al. (2014) Exploratory Structural Equation Modeling: an integration of the best features of exploratory and confirmatory factor analysis. Annual Review of Clinical Psychology 10: 85-110. 
McLaughlin T, Blum K, Steinberg B, et al. (2018) Pro-dopamine regulator, KB220Z, attenuates hoarding and shopping behavior in a female, diagnosed with SUD and ADHD. Journal of Behavioral Addictions 7: 192-203.

McLaughlin T, Oscar-Berman M, Simpatico T, et al. (2013) Hypothesizing repetitive paraphilia behavior of a medication refractive Tourette's syndrome patient having rapid clinical attenuation with KB220Znutrigenomic amino-acid therapy (NAAT). Journal of Behavioral Addictions 2: 117-124.

Mehroof M and Griffiths M. (2010) Online gaming addiction: the role of sensation seeking, self-control, neuroticism, aggression, state anxiety, and trait anxiety. Cyberpsychology, Behavior, and Social Networking 13: 313-316.

Meule A, de Zwaan M and Müller A. (2017) Attentional and motor impulsivity interactively predict 'food addiction' in obese individuals. Comprehensive Psychiatry 72: 83-87.

Müller KW, Beutel ME, Dreier M, et al. (2019) A clinical evaluation of the DSM-5 criteria for Internet Gaming Disorder and a pilot study on their applicability to further Internet-related disorders. Journal of Behavioral Addictions 8: 16-24.

Noble EP, Blum K, Ritchie T, et al. (1991) Allelic association of the D2 dopamine receptor gene with receptorbinding characteristics in alcoholism. Archives of General Psychiatry 48: 648-654.

Nower L, Derevensky JL and Gupta R. (2004) The relationship of impulsivity, sensation seeking, coping, and substance use in youth gamblers. Psychology of Addictive Behaviors 18: 49-55.

Nutt DJ, Lingford-Hughes A, Erritzoe D, et al. (2015) The dopamine theory of addiction: 40 years of highs and lows. Nature Reviews: Neuroscience 16: 305-312.

Patton JH, Stanford MS and Barratt ES. (1995) Factor structure of the Barratt impulsiveness scale. Journal of Clinical Psychiatry 51: 768-774.

Potenza MN. (2018) Searching for Replicable Dopamine-Related Findings in Gambling Disorder. Biological Psychiatry 83: 984-986.

Reise SP. (2012) The rediscovery of bifactor measurement models. Multivariate behavioral research 47: 667696.

Reise SP, Scheines R, Widaman KF, et al. (2013) Multidimensionality and structural coefficient bias in structural equation modeling: A bifactor perspective. Educational and Psychological Measurement 73: $5-26$.

Rømer Thomsen K, Callesen MB, Linnet J, et al. (2009) Severity of gambling is associated with severity of depressive symptoms in pathological gamblers. Behavioural Pharmacology 20: 527-536.

Sargent JD, Tanski S, Stoolmiller M, et al. (2010) Using sensation seeking to target adolescents for substance use interventions. Addiction 105: 506-514.

Shaffer HJ, LaPlante DA, LaBrie RA, et al. (2004) Toward a syndrome model of addiction: multiple expressions, common etiology. Harvard Review of Psychiatry 12: 367-374.

Smith JL, Mattick RP, Jamadar SD, et al. (2014) Deficits in behavioural inhibition in substance abuse and addiction: a meta-analysis. Drug and Alcohol Dependence 145: 1-33.

Stautz K and Cooper A. (2013) Impulsivity-related personality traits and adolescent alcohol use: A metaanalytic review. Clinical Psychology Review 33: 574-592.

Stephenson MT, Velez LF, Chalela P, et al. (2007) The reliability and validity of the Brief Sensation Seeking Scale (BSSS-8) with young adult Latino workers: implications for tobacco and alcohol disparity research. Addiction 102 Suppl 2: 79-91.

Ten Berge JM and Sočan G. (2004) The greatest lower bound to the reliability of a test and the hypothesis of unidimensionality. Psychometrika 69: 613-625.

Tinsley HEA and Tinsley DJ. (1987) Uses of factor analysis in counseling psychology research. Journal of Counseling Psychology 34: 414-424.

Varga G, Szekely A, Antal P, et al. (2012) Additive effects of serotonergic and dopaminergic polymorphisms on trait impulsivity. American Journal of Medical Genetics. Part B: Neuropsychiatric Genetics 159B: 281-288.

Verdejo-García A, Lawrence AJ and Clark L. (2008) Impulsivity as a vulnerability marker for substance-use disorders: Review of findings from high-risk research, problem gamblers and genetic association studies. Neuroscience and Biobehavioral Reviews 32: 777-810.

Weintraub D, Koester J, Potenza MN, et al. (2010) Impulse control disorders in Parkinson disease: a crosssectional study of 3090 patients. Archives of Neurology 67: 589-595.

Wills TA, Vaccaro D and McNamara G. (1994) Novelty seeking, risk taking, and related constructs as predictors of adolescent substance use: An application of Cloninger's theory. Journal of Substance Abuse 6: 1-20. 
Wills TA, Windle M and Cleary SD. (1998) Temperament and novelty seeking in adolescent substance use: Convergence of dimensions of temperament with constructs from Cloninger's theory. Journal of Personality and Social Psychology 74: 387-406.

Wingo T, Nesil T, Choi J-S, et al. (2016) Novelty seeking and drug addiction in humans and animals: from behavior to molecules. Journal of Neuroimmune Pharmacology 11: 456-470.

Yang BZ, Kranzler HR, Zhao H, et al. (2007) Association of haplotypic variants in DRD2, ANKK1, TTC12 and NCAM1 to alcohol dependence in independent case control and family samples. Human Molecular Genetics 16: 2844-2853.

Zilverstand A, Huang AS, Alia-Klein N, et al. (2018) Neuroimaging impaired response inhibition and salience attribution in human drug addiction: a systematic review. Neuron 98: 886-903.

Zuckerman M. (2007) Sensation seeking and risky behavior, Washington, DC, US: American Psychological Association. 
Table 1. Eigenvalues and fit indices of exploratory factor analyses in Subsample 1, Subsample 2, and Subsample 3.

\begin{tabular}{|c|c|c|c|c|c|c|c|c|c|c|c|c|c|c|c|}
\hline \multirow[b]{2}{*}{ Factors } & \multirow{2}{*}{$\begin{array}{c}\text { Sample } 1 \\
\text { Eigenvalues }\end{array}$} & \multirow{2}{*}{$\begin{array}{l}\text { Sample2 } \\
\text { Eigenvalues }\end{array}$} & \multirow{2}{*}{$\begin{array}{c}\text { Sample } 3 \\
\text { Eigenvalues* }\end{array}$} & \multicolumn{4}{|c|}{$\begin{array}{c}\text { Fit indices of different factor } \\
\text { solutions in Sample } 1\end{array}$} & \multicolumn{4}{|c|}{$\begin{array}{c}\text { Fit indices of different factor } \\
\text { solutions in Sample } 2\end{array}$} & \multicolumn{4}{|c|}{$\begin{array}{c}\text { Fit indices of different factor } \\
\text { solutions in Sample } 3 *\end{array}$} \\
\hline & & & & $\chi^{2}$ & $\mathrm{df}$ & RMSEA & TLI & $\chi^{2}$ & $\mathrm{df}$ & RMSEA & TLI & $\chi^{2}$ & $\mathrm{df}$ & RMSEA & TLI \\
\hline 1 & 10.32 & 9.73 & 9.29 & 4958 & 1224 & 0.085 & 0.625 & 5825 & 1224 & 0.094 & 0.478 & 1687 & 377 & 0.091 & 0.808 \\
\hline 2 & 4.52 & 5.00 & 2.37 & 3601 & 1174 & 0.070 & 0.746 & 3907 & 1174 & 0.074 & 0.677 & 1163 & 349 & 0.074 & 0.871 \\
\hline 3 & 3.75 & 3.66 & 1.87 & 2513 & 1125 & 0.054 & 0.848 & 2796 & 1125 & 0.059 & 0.794 & 852 & 322 & 0.062 & 0.909 \\
\hline 4 & 2.37 & 2.80 & 1.58 & 2009 & 1077 & 0.045 & 0.894 & 2130 & 1077 & 0.048 & 0.864 & 637 & 296 & 0.052 & 0.939 \\
\hline 5 & 1.90 & 2.02 & 1.37 & 1795 & 1030 & 0.042 & 0.909 & 1840 & 1030 & 0.043 & 0.891 & 501 & 271 & 0.045 & 0.953 \\
\hline 6 & 1.82 & 1.82 & 1.26 & 1599 & 984 & 0.038 & 0.923 & 1653 & 984 & 0.040 & 0.906 & 396 & 247 & 0.038 & 0.967 \\
\hline
\end{tabular}

Notes: Subsample $1 N=424$; Subsample $2 N=424$. Subsample $3 \mathrm{~N}=424$. Df=degree of freedom. RMSEA=Root Mean Square Error of Approximation.

TLI=Tucker-Lewis Index. *The analysis was performed on the selected items only. 
Table 2. Exploratory factor analyses of the $\mathbf{5 0}$ items with bifactor rotation on in Subsample 1 and Subsample 2.

General factor

F1

F2

F3

F4

\begin{tabular}{|c|c|c|c|c|c|c|c|c|c|c|}
\hline mo & $\begin{array}{l}\text { Subsam } \\
\text { ple } 1\end{array}$ & $\begin{array}{l}\text { Subsam } \\
\text { ple } 2\end{array}$ & $\begin{array}{l}\text { Subsam } \\
\text { ple } 1\end{array}$ & $\begin{array}{l}\text { Subsam } \\
\text { ple } 2\end{array}$ & $\begin{array}{l}\text { Subsam } \\
\text { ple } 1\end{array}$ & $\begin{array}{l}\text { Subsam } \\
\text { ple } 2\end{array}$ & $\begin{array}{l}\text { Subsam } \\
\text { ple } 1\end{array}$ & $\begin{array}{l}\text { Subsam } \\
\text { ple } 2\end{array}$ & $\begin{array}{l}\text { Subsam } \\
\text { ple } 1\end{array}$ & $\begin{array}{l}\text { Subsam } \\
\text { ple } 2\end{array}$ \\
\hline 1 & 0.15 & 0.19 & -0.08 & -0.10 & 0.14 & -0.06 & -0.04 & -0.12 & -0.11 & -0.02 \\
\hline 2 & 0.49 & 0.48 & 0.07 & -0.04 & 0.52 & -0.35 & -0.05 & 0.05 & 0.03 & 0.23 \\
\hline 4 & 0.35 & 0.24 & 0.02 & 0.10 & 0.02 & -0.05 & 0.08 & -0.12 & 0.32 & 0.46 \\
\hline 5 & 0.21 & 0.24 & -0.12 & -0.11 & 0.54 & -0.42 & 0.02 & -0.20 & 0.01 & 0.07 \\
\hline 6 & 0.67 & 0.62 & 0.15 & 0.14 & 0.14 & -0.16 & -0.08 & 0.10 & 0.22 & 0.30 \\
\hline 8 & -0.06 & 0.07 & 0.74 & 0.63 & -0.15 & 0.18 & 0.00 & -0.03 & 0.01 & 0.01 \\
\hline 9 & 0.29 & 0.40 & 0.14 & $\mathbf{- 0 . 0 7}$ & -0.05 & 0.28 & 0.05 & -0.04 & $\mathbf{- 0 . 0 3}$ & $\mathbf{- 0 . 0 7}$ \\
\hline 10 & 0.10 & 0.17 & 0.41 & 0.49 & 0.15 & 0.02 & 0.13 & -0.05 & -0.13 & -0.20 \\
\hline 11 & 0.35 & 0.34 & -0.18 & 0.05 & -0.08 & $\mathbf{- 0 . 0 7}$ & 0.07 & 0.05 & 0.05 & 0.14 \\
\hline 12 & 0.16 & 0.46 & -0.08 & 0.02 & -0.05 & 0.03 & 0.81 & -0.35 & -0.02 & -0.42 \\
\hline 13 & 0.02 & 0.17 & 0.60 & 0.54 & 0.10 & -0.01 & -0.03 & 0.01 & 0.01 & -0.14 \\
\hline 14 & -0.23 & -0.17 & -0.12 & -0.18 & 0.15 & -0.27 & 0.11 & -0.09 & -0.15 & -0.16 \\
\hline 15 & 0.06 & 0.15 & 0.12 & -0.06 & 0.34 & -0.17 & 0.26 & 0.04 & -0.25 & -0.40 \\
\hline 16 & 0.67 & 0.59 & 0.11 & 0.11 & -0.17 & -0.10 & 0.03 & 0.31 & -0.10 & -0.06 \\
\hline 18 & 0.01 & 0.08 & 0.37 & 0.39 & -0.34 & 0.47 & 0.03 & -0.06 & 0.03 & 0.08 \\
\hline 19 & -0.05 & 0.00 & 0.34 & 0.37 & -0.02 & -0.07 & 0.03 & 0.09 & -0.07 & -0.05 \\
\hline 20 & 0.39 & 0.30 & 0.06 & 0.00 & -0.33 & 0.31 & 0.03 & 0.30 & -0.08 & 0.18 \\
\hline 22 & 0.21 & 0.46 & 0.16 & 0.24 & 0.12 & -0.04 & 0.48 & -0.27 & 0.14 & -0.29 \\
\hline 23 & 0.70 & 0.53 & -0.10 & -0.31 & -0.03 & 0.21 & -0.03 & 0.33 & -0.19 & -0.04 \\
\hline 25 & 0.29 & 0.25 & 0.04 & 0.02 & -0.36 & 0.41 & 0.06 & -0.03 & 0.44 & 0.54 \\
\hline
\end{tabular}


$\begin{array}{lllllllllll}29 & 0.35 & 0.40 & -0.01 & -0.62 & 0.01 & 0.55 & -0.24 & -0.01 & -0.20 & -0.04\end{array}$ $\begin{array}{lllllllllll}30 & -0.16 & -0.05 & 0.21 & 0.32 & -0.32 & 0.35 & 0.07 & 0.05 & -0.11 & -0.06\end{array}$

$\begin{array}{lllllllllll}31 & 0.74 & 0.47 & 0.06 & -0.01 & -0.33 & 0.06 & -0.07 & 0.72 & -0.31 & -0.07\end{array}$

$\begin{array}{lllllllllll}32 & 0.66 & 0.60 & -0.01 & -0.12 & 0.12 & -0.21 & 0.03 & 0.26 & -0.04 & 0.14\end{array}$

$\begin{array}{lllllllllll}34 & 0.21 & 0.50 & 0.01 & 0.03 & 0.01 & 0.02 & 0.65 & -0.33 & 0.01 & -0.34\end{array}$

$\begin{array}{lllllllllll}35 & 0.23 & 0.22 & 0.01 & -0.08 & 0.44 & -0.32 & 0.20 & -0.15 & -0.01 & -0.06\end{array}$

$\begin{array}{lllllllllll}36 & 0.45 & 0.62 & 0.05 & -0.10 & -0.30 & 0.37 & 0.14 & 0.01 & 0.08 & -0.03\end{array}$

$\begin{array}{lllllllllll}37 & -0.28 & -0.27 & 0.06 & 0.14 & -0.26 & 0.21 & -0.05 & 0.06 & -0.06 & -0.12\end{array}$

$\begin{array}{lllllllllll}38 & 0.49 & 0.49 & -0.01 & -0.64 & 0.03 & 0.54 & -0.19 & 0.00 & -0.14 & 0.01\end{array}$

$\begin{array}{lllllllllll}39 & 0.53 & 0.45 & -0.06 & -0.18 & -0.01 & 0.17 & 0.17 & 0.01 & 0.16 & 0.05\end{array}$

$\begin{array}{lllllllllll}40 & 0.74 & 0.66 & 0.06 & 0.07 & -0.10 & 0.04 & -0.05 & 0.35 & 0.18 & 0.19\end{array}$ $\begin{array}{lllllllllll}41 & 0.39 & 0.38 & 0.05 & 0.14 & 0.01 & 0.01 & -0.03 & -0.04 & 0.74 & 0.71\end{array}$

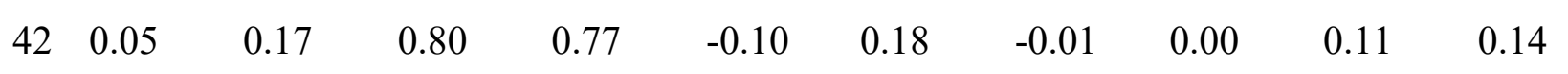
$\begin{array}{lllllllllll}43 & -0.08 & -0.26 & 0.12 & 0.10 & -0.20 & 0.15 & -0.23 & 0.08 & 0.07 & 0.25\end{array}$ $\begin{array}{lllllllllll}44 & 0.78 & 0.53 & -0.04 & 0.07 & -0.41 & -0.06 & -0.06 & 0.72 & -0.31 & -0.05\end{array}$ $\begin{array}{lllllllllll}46 & 0.06 & 0.22 & 0.74 & 0.74 & -0.03 & 0.14 & -0.01 & -0.02 & -0.03 & -0.01\end{array}$ $\begin{array}{lllllllllll}48 & -0.09 & 0.14 & 0.39 & 0.34 & 0.07 & 0.04 & 0.17 & -0.12 & -0.22 & -0.26\end{array}$ $\begin{array}{lllllllllll}49 & 0.79 & 0.75 & -0.01 & -0.11 & 0.06 & -0.12 & 0.01 & 0.24 & 0.07 & 0.14\end{array}$ $\begin{array}{lllllllllll}50 & 0.50 & 0.44 & -0.09 & -0.16 & 0.48 & -0.39 & -0.05 & -0.11 & 0.20 & 0.18\end{array}$ $\begin{array}{lllllllllll}51 & 0.47 & 0.44 & -0.29 & -0.35 & 0.15 & -0.02 & 0.19 & -0.05 & -0.06 & -0.04\end{array}$ $\begin{array}{lllllllllll}52 & 0.61 & 0.53 & -0.02 & 0.02 & -0.18 & 0.19 & 0.10 & 0.17 & 0.32 & 0.31\end{array}$ $\begin{array}{lllllllllll}54 & 0.85 & 0.67 & -0.09 & -0.13 & -0.06 & 0.06 & -0.03 & 0.47 & -0.10 & -0.03\end{array}$ $\begin{array}{lllllllllll}55 & 0.41 & 0.52 & 0.23 & 0.17 & 0.21 & -0.06 & 0.24 & 0.06 & 0.03 & -0.23\end{array}$ $\begin{array}{lllllllllll}57 & 0.48 & 0.56 & -0.01 & 0.03 & 0.07 & -0.08 & 0.27 & -0.07 & -0.06 & -0.12\end{array}$ $\begin{array}{lllllllllll}58 & 0.42 & 0.42 & -0.01 & 0.00 & 0.08 & -0.03 & -0.01 & -0.15 & 0.62 & 0.63\end{array}$ $\begin{array}{lllllllllll}59 & 0.52 & 0.44 & -0.25 & -0.33 & 0.02 & 0.03 & 0.16 & -0.04 & -0.02 & 0.04\end{array}$ 


$\begin{array}{lllllllllll}\mathbf{6 2} & \mathbf{0 . 7 1} & \mathbf{0 . 5 8} & \mathbf{- 0 . 0 2} & \mathbf{0 . 1 2} & \mathbf{- 0 . 2 7} & \mathbf{0 . 0 4} & \mathbf{- 0 . 0 3} & \mathbf{0 . 3 9} & \mathbf{- 0 . 0 6} & \mathbf{0 . 0 5} \\ \mathbf{6 4} & \mathbf{0 . 6 5} & \mathbf{0 . 6 2} & \mathbf{- 0 . 1 0} & \mathbf{- 0 . 0 6} & \mathbf{- 0 . 0 2} & \mathbf{- 0 . 0 7} & \mathbf{0 . 2 5} & \mathbf{0 . 0 3} & \mathbf{0 . 0 1} & \mathbf{- 0 . 0 9} \\ 65 & 0.12 & 0.47 & 0.03 & 0.06 & -0.07 & 0.06 & 0.82 & -0.43 & 0.02 & -0.44 \\ 68 & 0.31 & 0.27 & 0.00 & -0.04 & 0.27 & -0.11 & 0.04 & 0.02 & -0.01 & -0.10 \\ 70 & 0.10 & 0.19 & 0.02 & 0.03 & 0.46 & -0.41 & 0.19 & -0.02 & -0.18 & -0.20\end{array}$

Notes: Reported values are factor loadings of the exploratory factor analysis on Subsample 1 $(N=424)$ and Subsample $2(N=424)$. Boldfaced items were selected for further analyses. Numbering of the 51 items follows the numbering of the original 72 item version. 
Table 3. Exploratory factor analysis of the selected items on Subsample 3.
F1
F2
F3
F4

General Lack of Risk-

$\begin{array}{lllll}\text { factor } & \text { sexual } & \text { seeking } & \text { Activity } & \text { Social } \\ & \text { satisfaction } & \text { behavior } & & \text { concerns }\end{array}$

\begin{tabular}{|c|c|c|c|c|c|}
\hline 38 & $\begin{array}{l}\text { It can happen that I have more than one sexual } \\
\text { partner at once. }\end{array}$ & 0.54 & 0.56 & -0.08 & -0.06 \\
\hline 9 & I can never get enough sex. & 0.34 & 0.48 & 0.01 & 0.02 \\
\hline 29 & I regularly change my sexual partners. & 0.46 & 0.45 & -0.07 & -0.14 \\
\hline
\end{tabular}

\begin{tabular}{|c|c|c|c|c|c|c|}
\hline 44 & Extreme sports stimulate me. & 0.63 & -0.06 & 0.70 & -0.10 & 0.06 \\
\hline 31 & I like experimenting with extreme sports. & 0.61 & -0.02 & 0.60 & -0.06 & -0.04 \\
\hline 20 & I've tried many sports in my life. & 0.27 & 0.11 & 0.45 & 0.05 & -0.09 \\
\hline 62 & $\begin{array}{l}\text { I look for extreme challenges in my work, } \\
\text { sports, or anything else. }\end{array}$ & 0.68 & -0.06 & 0.42 & 0.16 & 0.02 \\
\hline 54 & I like to live dangerously. & 0.74 & 0.13 & 0.37 & -0.02 & 0.07 \\
\hline 41 & I cannot stand inactivity. & 0.41 & -0.03 & -0.06 & 0.64 & -0.03 \\
\hline 25 & I'm almost always active. & 0.22 & 0.04 & 0.03 & 0.55 & 0.01 \\
\hline 58 & Being inactive really annoys me. & 0.44 & -0.03 & -0.17 & 0.52 & 0.03 \\
\hline 52 & Most people think I can't sit still. & 0.47 & 0.06 & 0.19 & 0.46 & 0.04 \\
\hline 4 & $\begin{array}{l}\text { While doing a task or work, I find myself } \\
\text { already planning the next task. }\end{array}$ & 0.31 & -0.14 & -0.10 & 0.40 & -0.03 \\
\hline 51 & $\begin{array}{l}\text { My friends and family often worry about my } \\
\text { lifestyle. }\end{array}$ & 0.51 & 0.03 & -0.05 & 0.00 & 0.56 \\
\hline 59 & $\begin{array}{l}\text { My friends or my family warned me several } \\
\text { times that I overdo my recreational activities. }\end{array}$ & 0.55 & -0.04 & 0.05 & 0.07 & 0.52 \\
\hline 50 & $\begin{array}{l}\text { If nothing special happens during the day, I feel } \\
\text { empty and bored. }\end{array}$ & 0.43 & $-\mathbf{0 . 3 3}$ & -0.24 & -0.01 & 0.03 \\
\hline
\end{tabular}


36

I desire to participate in all aspects of life no

matter the limits.

2 I don't receive gratification from everyday life.

16

I like activities that'll give me an adrenaline rush.

40 I like to be always active.

I consistently seek new situations and

6 adventures.

23 Others would consider my activities dangerous. Often I want to feel stimulated no matter what I

64 have to do to get it.

49 I need more excitement than others.

57

I often want a good time no matter what I have

to do to get it.

39

No pain or tiredness can deter me from doing

something that I am passionate about.

friends rather than just talking with each other.

32 I need more stimulation than others.

55

When I'm doing something pleasurable I can hardly stop myself. $\begin{array}{lllll}0.59 & \mathbf{0 . 3 1} & 0.01 & 0.03 & \mathbf{- 0 . 3 5}\end{array}$

$\begin{array}{lllll}\mathbf{0 . 4 9} & -0.29 & -0.11 & -0.03 & -0.12\end{array}$

$\begin{array}{lllll}\mathbf{0 . 6 4} & -0.10 & \mathbf{0 . 2 5} & -0.04 & -0.13\end{array}$

$\begin{array}{lllll}\mathbf{0 . 6 2} & 0.11 & 0.16 & \mathbf{0 . 2 4} & -0.14\end{array}$

$\begin{array}{lllll}\mathbf{0 . 6 2} & -0.18 & -0.09 & 0.13 & \mathbf{- 0 . 2 4}\end{array}$

$\begin{array}{lllll}\mathbf{0 . 6 3} & 0.21 & 0.19 & 0.06 & 0.24\end{array}$

$\begin{array}{lllll}0.74 & 0.03 & -0.10 & -0.11 & 0.22\end{array}$

$\begin{array}{lllll}\mathbf{0 . 7 8} & -0.29 & 0.04 & 0.02 & -0.16\end{array}$

$\begin{array}{lllll}\mathbf{0 . 5 9} & 0.00 & -0.24 & -0.21 & 0.15\end{array}$

$\begin{array}{lllll}\mathbf{0 . 5 0} & 0.1 & 0.03 & -0.09 & 0.15\end{array}$

$\begin{array}{lllll}0.29 & 0.03 & -0.03 & 0.01 & -0.09\end{array}$

$\begin{array}{lllll}\mathbf{0 . 6 9} & -0.19 & 0.08 & -0.02 & -0.07\end{array}$

$\begin{array}{lllll}\mathbf{0 . 3 7} & 0.14 & -0.10 & -0.02 & 0.00\end{array}$

Notes: Reported values are factor loadings of the exploratory factor analysis on Subsample 3

$(\mathrm{N}=424)$. Numbering of the 51 items follows the numbering of the original 72-item version. 
Table 4. Exploratory structural equation modeling of selected items in Subsample 4.

\begin{tabular}{|c|c|c|c|c|c|c|}
\hline & Item & $\begin{array}{l}\text { Reward } \\
\text { deficiency } \\
\text { tendency }\end{array}$ & $\begin{array}{l}\text { Lack of } \\
\text { sexual } \\
\text { satisfaction }\end{array}$ & Activity & $\begin{array}{l}\text { Social } \\
\text { concerns }\end{array}$ & $\begin{array}{l}\text { Risk- } \\
\text { seeking } \\
\text { behavior }\end{array}$ \\
\hline 29 & I regularly change my sexual partners. & 0.47 & 0.63 & -0.03 & 0.03 & 0.03 \\
\hline 38 & $\begin{array}{l}\text { It can happen that I have more than one } \\
\text { sexual partner at once. }\end{array}$ & 0.47 & 0.71 & -0.18 & 0.08 & -0.01 \\
\hline 9 & I can never get enough sex. & 0.40 & 0.26 & -0.11 & -0.18 & -0.01 \\
\hline 4 & $\begin{array}{l}\text { While doing a task or work, I find } \\
\text { myself already planning the next task. }\end{array}$ & 0.39 & -0.02 & $\mathbf{0 . 3 0}$ & 0.00 & -0.16 \\
\hline 25 & I'm almost always active. & 0.24 & -0.05 & 0.42 & -0.19 & 0.07 \\
\hline 41 & I cannot stand inactivity. & 0.47 & -0.21 & 0.73 & -0.11 & -0.06 \\
\hline 52 & Most people think I can't sit still. & 0.65 & 0.06 & 0.21 & 0.09 & 0.07 \\
\hline 58 & Being inactive really annoys me. & 0.39 & 0.00 & 0.60 & 0.02 & -0.08 \\
\hline 51 & $\begin{array}{l}\text { My friends and family often worry about } \\
\text { my lifestyle. }\end{array}$ & 0.45 & 0.03 & -0.17 & 0.46 & -0.19 \\
\hline 59 & $\begin{array}{l}\text { My friends or my family warned me } \\
\text { several times that I overdo my } \\
\text { recreational activities. }\end{array}$ & 0.42 & 0.02 & -0.08 & 0.62 & -0.02 \\
\hline 20 & I've tried many sports in my life. & 0.40 & 0.14 & 0.10 & -0.09 & 0.50 \\
\hline 31 & Extreme sports stimulate me. & 0.60 & -0.01 & -0.10 & -0.09 & 0.66 \\
\hline 44 & I like to live dangerously. & 0.66 & -0.07 & -0.07 & -0.04 & 0.57 \\
\hline 54 & $\begin{array}{l}\text { I look for extreme challenges in my } \\
\text { work, sports, or anything else. }\end{array}$ & 0.82 & 0.08 & -0.23 & 0.09 & 0.09 \\
\hline 62 & $\begin{array}{l}\text { I like experimenting with extreme } \\
\text { sports. }\end{array}$ & 0.69 & -0.07 & -0.05 & 0.06 & 0.30 \\
\hline
\end{tabular}


I don't receive gratification from

everyday life.

0.47

I consistently seek new situations and

6 adventures.

11

I like activities that'll give me an adrenaline rush.

I prefer being active when going out

16 with friends rather than just talking with

each other.

I desire to participate in all aspects of

23

life no matter the limits.

Others would consider my activities

32

dangerous.

36 I like to be always active.

0.62

39 I need more stimulation than others.

0.60

No pain or tiredness can deter me from

40 doing something that I am passionate about.

49 I need more excitement than others.

If nothing special happens during the day, I feel empty and bored.

I often want a good time no matter what I have to do to get it.

When I'm doing something pleasurable,

I can hardly stop myself.

64

Often, I want to feel stimulated no

matter what I have to do to get it.

\begin{tabular}{lccccc}
\hline \hline Explained common variance & $68 \%$ & $8 \%$ & $10 \%$ & $5 \%$ & $9 \%$ \\
Omega $^{\#}$ & 0.97 & 0.75 & 0.79 & 0.66 & 0.82
\end{tabular}


Omega hierarchical ${ }^{\# \#}$

0.94

0.55

0.41

0.40

0.27

Notes: $\mathrm{N}=454$. The upper part of the table presents the factor loadings. The salient factor loadings

$(0.30<)$ are in bold type. The rotation was target (orthogonal), correlations among specific factors were set to zero.

\#Omega refers to the proportion of explained variance in the scale score attributed to the global and specific factors.

\#\#Omega hierarchical refers to the proportion of explained variance of the scale score attributed to the specific factor. Numbering of the 51 items follows the numbering of the original 72 -item version. 
Table 5. Confirmatory factor analysis of the Reward Deficiency Syndrome Questionnaire

(RDSQ-29) in an independent university sample (Sample2).

\begin{tabular}{|c|c|c|c|c|c|c|}
\hline & Item & $\begin{array}{l}\text { Reward } \\
\text { deficiency } \\
\text { trait }\end{array}$ & $\begin{array}{l}\text { Lack of } \\
\text { sexual } \\
\text { satisfaction }\end{array}$ & Activity & $\begin{array}{l}\text { Social } \\
\text { concerns }\end{array}$ & $\begin{array}{l}\text { Risk- } \\
\text { seeking } \\
\text { behavior }\end{array}$ \\
\hline 11 & I regularly change my sexual partners. & 0.58 & 0.74 & & & \\
\hline 16 & $\begin{array}{l}\text { It can happen that I have more than one } \\
\text { sexual partner at once. }\end{array}$ & 0.54 & 0.72 & & & \\
\hline 6 & I can never get enough sex. & 0.27 & 0.34 & & & \\
\hline 2 & $\begin{array}{l}\text { While doing a task or work, I find myself } \\
\text { already planning the next task. }\end{array}$ & 0.32 & & 0.34 & & \\
\hline 7 & I'm almost always active. & 0.35 & & 0.60 & & \\
\hline 17 & I cannot stand inactivity. & 0.48 & & 0.74 & & \\
\hline 22 & Most people think I can't sit still. & 0.68 & & 0.34 & & \\
\hline 26 & Being inactive really annoys me. & 0.47 & & 0.58 & & \\
\hline 13 & $\begin{array}{l}\text { My friends and family often worry about } \\
\text { my lifestyle. }\end{array}$ & 0.56 & & & 0.56 & \\
\hline 18 & $\begin{array}{l}\text { My friends or my family warned me } \\
\text { several times that I overdo my } \\
\text { recreational activities. }\end{array}$ & 0.56 & & & 0.56 & \\
\hline 9 & I've tried many sports in my life. & 0.52 & & & & 0.41 \\
\hline 19 & Extreme sports stimulate me. & 0.63 & & & & 0.61 \\
\hline 23 & I like to live dangerously. & 0.80 & & & & 0.30 \\
\hline 27 & $\begin{array}{l}\text { I look for extreme challenges in my work, } \\
\text { sports, or anything else. }\end{array}$ & 0.74 & & & & 0.31 \\
\hline 14 & I like experimenting with extreme sports. & 0.57 & & & & 0.82 \\
\hline
\end{tabular}


If nothing special happens during the day,

I feel empty and bored.

I don't receive gratification from

1

everyday life.

I consistently seek new situations and

3

adventures.

I like activities that'll give me an

4

adrenaline rush.

I prefer being active when going out with

5 friends rather than just talking with each

other.

I desire to participate in all aspects of life no matter the limits.

Others would consider my activities

10

dangerous.

12 I like to be always active.

15 I need more stimulation than others.

No pain or tiredness can deter me from

20 doing something that I am passionate about.

24 I need more excitement than others.

I often want a good time no matter what I

have to do to get it.

When I'm doing something pleasurable, I

28

can hardly stop myself.

Often, I want to feel stimulated no matter

29 what I have to do to get it.

\begin{tabular}{lccccc}
\hline \hline Explained common variance & $69 \%$ & $8 \%$ & $10 \%$ & $4 \%$ & $9 \%$ \\
Omega\# & 0.96 & 0.82 & 0.83 & 0.77 & 0.86
\end{tabular}


Notes: $\mathrm{N}=253$. The upper part of the table presents the factor loadings. For identification, the factor loadings of Items 13 and 18 were constrained to be equal. Specific factors were orthogonal (correlations among them were set to zero). Error covariance was allowed between Items 25 and 29. Numbering of the items present the final 29-item version of RDSQ.

\#Omega refers to the proportion of explained variance in the scale score attributed to the global and specific factors. \#\#Omega hierarchical refers to the proportion of explained variance of the scale score attributed to the specific factor. 
Table 6. Construct validity of Reward Deficiency Syndrome Questionnaire (RDSQ-29):

Confirmatory factor analysis with covariates.

Reward deficiency tendency behavior

Full model

\begin{tabular}{llllll}
\hline Gender & $\mathbf{0 . 1 1} * *$ & 0.09 & $\mathbf{- 0 . 2 5} * * *$ & 0.13 & 0.08 \\
Sensation- & $\mathbf{0 . 5 8 * * *}$ & 0.03 & $\mathbf{- 0 . 2 6 * *}$ & $-0.22 *$ & $\mathbf{0 . 3 9 * * *}$ \\
seeking & & & & \\
Impulsivity & $\mathbf{0 . 2 2} * * *$ & 0.03 & $\mathbf{- 0 . 2 4 * *}$ & $0.30 * *$ & -0.02 \\
\hline $\mathrm{R}^{2}$ & $51.4 \%$ & $1.1 \%$ & $24.5 \%$ & $9.2 \%$ & $15.3 \%$
\end{tabular}

Partial model 1

Gender $\quad \mathbf{0 . 1 0}$ *

Sensation-

seeking

\section{$0.59 * * *$}

Impulsivity $\quad \mathbf{0 . 2 0} * * *$

$\mathrm{R}^{2} \quad 50.1 \%$

\section{Partial Model 2}

Gender

0.15

$-0.11$

$0.20^{*}$

0.13*

Sensation-

seeking

\begin{tabular}{|c|c|}
\hline $0.42 * * *$ & $0.46 * * *$ \\
\hline
\end{tabular}

Impulsivity

0.17

0.02

$0.43 * * *$

$0.14^{*}$

$\mathrm{R}^{2}$

$29.7 \%$

$22.5 \%$

$39.9 \%$

$57.7 \%$

Notes: Standardized regression coefficients. Males were coded as 2 in the database. ${ }^{*} p<0.05$; $* * p<0.01 ; * * * p<0.001$. 
Table 7: Descriptive statistics of the RDSQ on Sample 1 and Sample 2.

\begin{tabular}{|c|c|c|c|c|c|c|}
\hline \multirow{4}{*}{$\mathrm{N}$} & \multirow{4}{*}{ Mean } & \multirow{3}{*}{ Std. } & & \multicolumn{2}{|r|}{ Total } & Total \\
\hline & & & & Cohen's & & sample \\
\hline & & & $\mathrm{p}$ & & sample & \\
\hline & & Deviation & & d & mean & $\begin{array}{c}\text { std. } \\
\text { deviation }\end{array}$ \\
\hline
\end{tabular}

\begin{tabular}{|c|c|c|c|c|c|c|c|c|}
\hline Sample 1 & & & & & & & & \\
\hline Reward & Males & 740 & 2.12 & 0.45 & & & & \\
\hline $\begin{array}{l}\text { dependency } \\
\text { (RDS) }\end{array}$ & Females & 989 & 2.03 & 0.43 & $<0.001$ & 0.21 & 2.07 & 0.44 \\
\hline Lack of sexual & Males & 740 & 1.85 & 0.59 & & & & \\
\hline satisfaction & Females & 985 & 1.63 & 0.50 & $<0.001$ & 0.38 & 1.72 & 0.55 \\
\hline Activity & $\begin{array}{l}\text { Males } \\
\text { Females }\end{array}$ & $\begin{array}{l}740 \\
989\end{array}$ & $\begin{array}{l}2.37 \\
2.48\end{array}$ & $\begin{array}{l}0.60 \\
0.63\end{array}$ & $<0.001$ & 0.18 & 2.43 & 0.62 \\
\hline Social concerns & $\begin{array}{l}\text { Males } \\
\text { Females }\end{array}$ & 735 & 1.78 & $\begin{array}{l}0.74 \\
0.67\end{array}$ & $<0.001$ & 0.37 & 1.63 & 0.71 \\
\hline $\begin{array}{l}\text { Risk seeking } \\
\text { behavior }\end{array}$ & Males & 740 & 2.02 & 0.73 & $<0.001$ & 0.27 & 1.91 & 0.7 \\
\hline & Females & 988 & 1.83 & 0.67 & & & & \\
\hline
\end{tabular}

\section{Sample 2}

\begin{tabular}{|c|c|c|c|c|c|c|c|c|}
\hline Reward & Males & 69 & 2.14 & 0.46 & & & & \\
\hline $\begin{array}{l}\text { dependency } \\
\text { (RDS) }\end{array}$ & Females & 184 & 1.98 & 0.43 & 0.014 & 0.36 & 2.02 & 0.45 \\
\hline Lack of sexual & Males & 69 & 1.82 & 0.65 & & & & \\
\hline satisfaction & Females & 184 & 1.66 & 0.52 & 0.074 & 0.27 & 1.71 & 0.57 \\
\hline Activity & Males & 69 & 2.56 & 0.63 & n.s. & 0.10 & 2.6 & 0.64 \\
\hline
\end{tabular}




\begin{tabular}{|c|c|c|c|c|c|c|c|c|}
\hline & Females & 184 & 2.62 & 0.64 & & & & \\
\hline \multirow{3}{*}{ Social concerns } & Males & 69 & 1.82 & 0.74 & \multirow{3}{*}{0.041} & \multirow{3}{*}{0.28} & \multirow{3}{*}{1.67} & \multirow{3}{*}{0.7} \\
\hline & & & & & & & & \\
\hline & Females & 184 & 1.62 & 0.68 & & & & \\
\hline Risk seeking & Males & 69 & 2.06 & 0.74 & \multirow[b]{2}{*}{0.005} & \multirow[b]{2}{*}{0.39} & \multirow[b]{2}{*}{1.86} & \multirow[b]{2}{*}{0.69} \\
\hline behavior & Females & 184 & 1.79 & 0.66 & & & & \\
\hline
\end{tabular}

Note: $\mathrm{RDS}=$ Reward Dependency Scale. 


\section{Appendix 1}

\section{Reward Deficiency Syndrome Questionnaire (RDSQ-29)}

Instuction: Below is a list of statements referring to everyday human behaviors. Simply indicate the extent to which each of the statements is true of yourself. There are no right or wrong answers.

\begin{tabular}{|c|c|c|c|c|c|}
\hline & & 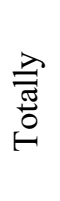 & 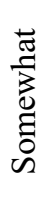 & 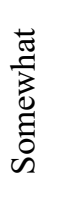 & 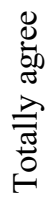 \\
\hline 1 & I don't receive gratification from everyday life. & 1 & 2 & 3 & 4 \\
\hline 2 & While doing a task or work, I find myself already planning the next task. & 1 & 2 & 3 & 4 \\
\hline 3 & I consistently seek new situations and adventures. & 1 & 2 & 3 & 4 \\
\hline 4 & I like activities that'll give me an adrenaline rush. & 1 & 2 & 3 & 4 \\
\hline 5 & I prefer being active when going out with friends rather than just talking with each other. & 1 & 2 & 3 & 4 \\
\hline 6 & I can never get enough sex. & 1 & 2 & 3 & 4 \\
\hline 7 & I'm almost always active. & 1 & 2 & 3 & 4 \\
\hline 8 & I desire to participate in all aspects of life no matter the limits. & 1 & 2 & 3 & 4 \\
\hline 9 & I've tried many sports in my life. & 1 & 2 & 3 & 4 \\
\hline 10 & Others would consider my activities dangerous. & 1 & 2 & 3 & 4 \\
\hline 11 & I regularly change my sexual partners. & 1 & 2 & 3 & 4 \\
\hline 12 & I like to be always active. & 1 & 2 & 3 & 4 \\
\hline 13 & My friends and family often worry about my lifestyle. & 1 & 2 & 3 & 4 \\
\hline 14 & I like experimenting with extreme sports. & 1 & 2 & 3 & 4 \\
\hline 15 & I need more stimulation than others. & 1 & 2 & 3 & 4 \\
\hline 16 & It can happen that I have more than one sexual partner at once. & 1 & 2 & 3 & 4 \\
\hline 17 & I cannot stand inactivity. & 1 & 2 & 3 & 4 \\
\hline 18 & My friends or my family warned me several times that I overdo my recreational activities. & 1 & 2 & 3 & 4 \\
\hline
\end{tabular}




\begin{tabular}{|c|c|c|c|c|c|}
\hline 19 & Extreme sports stimulate me. & 1 & 2 & 3 & 4 \\
\hline 20 & No pain or tiredness can deter me from doing something that I am passionate about. & 1 & 2 & 3 & 4 \\
\hline 21 & If nothing special happens during the day, I feel empty and bored. & 1 & 2 & 3 & 4 \\
\hline 22 & Most people think I can't sit still. & 1 & 2 & 3 & 4 \\
\hline 23 & I like to live dangerously. & 1 & 2 & 3 & 4 \\
\hline 24 & I need more excitement than others. & 1 & 2 & 3 & 4 \\
\hline 25 & I often want a good time no matter what I have to do to get it. & 1 & 2 & 3 & 4 \\
\hline 26 & Being inactive really annoys me. & 1 & 2 & 3 & 4 \\
\hline 27 & I look for extreme challenges in my work, sports, or anything else. & 1 & 2 & 3 & 4 \\
\hline 28 & When I'm doing something pleasurable I can hardly stop myself. & 1 & 2 & 3 & 4 \\
\hline 29 & Often I want to feel stimulated no matter what I have to do to get it. & 1 & 2 & 3 & 4 \\
\hline
\end{tabular}

Scoring: Reward Deficiency Trait is computed by taking the mean of all the 29 items.

Scoring of the subscales is calculated by taking the mean of specific items:

1. Lack of sexual satisfaction: $6,11,16$ items;

2. Activity: 2, 7, 17, 22, 26 items;

3. Social concerns: 13, 18 items;

4. Risk seeking behavior: 9, 14, 19, 23, 27 items 